\section{MedienPädagogik}

www. medienpaed.com
Zeitschrift für

Theorie und Praxis

der Medienbildung

ISSN 1424-3636

\title{
How to Define Media in a Mediatized Society? A Media Pedagogical Proposal Inspired by Theoretical Ideas of Castells, Luhmann and Peirce
}

\author{
Bardo Herzig and Sandra Aßmann
}

\begin{abstract}
Learning processes of children, adolescents and adults do not only take place in formal contexts like school, but also in informal contexts, such as in the family or in one's peer group, or in non-formal social contexts like clubs. In many of these learning processes media play a significant role - as an instrument and as a subject for learning. Therefore it is an important task for media education to describe and analyze such processes and to formulate pedagogical consequences for learning with and about media. To realize this challenge, it is helpful and necessary to develop a definition of media which is adequate for learning in different contexts of a mediatized society. We discuss three theoretical approaches: a network perspective, systems theory and semiotics to help us to create an appropriate definition of media offers. We use an everyday life example (communication with and via Facebook) to illustrate our argument.
\end{abstract}

\section{Introduction}

Different theorists recognize the ubiquity of media in contemporary society. In terms of «Mediatization» (e. g. Krotz 2008) or «Mediatic turn» (e. g. Friesen and Hug 2009) scholars attempt to describe the transition of using media between former generations and the current one.

Nowadays, the everyday life of children and adolescents is interpenetrated by media. They use media devices to communicate, to be entertained, to inform themselves, et cetera. A life without media seems to be unimaginable. Media are incorporated in ordinary life. Young people are growing up in different environments, which offer different learning opportunities. Media play a special role in the formal and informal educational contexts of children and adolescents because media are an essential part of their culture with their families, their friends and within their schools (e.g. Livingstone and Bovill 2001). In many European countries there is a clear difference between high media access and frequent use at home, and minor access and less frequent use in schools, in particular in Germany (cf. Herzig and Grafe 2007; EuroMeduc 2009). All in all, there seems to be a gap between the media use in different educational contexts of young people, which is difficult to bridge. Currently, there is a need for further research about the media cultures and 
practices of children and adolescents in formal and informal educational contexts and especially about how the gaps can be bridged and how the change in society's media culture can be integrated into schools (cf. BMFSJ 2005).

If we focus on these gaps from a media pedagogical point of view it is necessary to point out a clear understanding of «media» as well as a precise understanding of «contexts».

Therefore, we present a definition of media which is sustainable for both, analog and digital media (Herzig 2012). This definition is interdisciplinary. An important condition is the possibility to describe elementary processes of computer sciences as semiotic processes. Software development is one example that is adequate to illustrate this assumption.

The theoretical basis of the definition consists of Peirce's ideas about semiotics and Luhmann's sociological systems theory. Media (devices and products) can be characterized as patterns, which are readable as signs. These patterns are able to offer cognitive systems the potential of creating meaning and producing knowledge. On the one hand they are inscribed in technology or materiality; on the other hand they can be presented, saved, broadcasted or manipulated with technological support.

To analyze the gaps between learning in formal and informal contexts we apply this definition of media on a specific understanding of contexts. We concentrate on the interpenetration of contexts as networks by Castells on one side and the perspective of contexts as socials systems by Luhmann on the other side. In this way, we create a theoretical framework that allows us to do research on acting and learning with media of children and adolescents in their everyday life.

\section{Media in an Everyday Life Situation}

Today's students and teachers do not only meet each other in school or occasionally in private (e.g. downtown). Nowadays they have many possibilities to meet in the virtual world, especially in social networks like Facebook. There are different ways of dealing with this development. In Germany there are few official recommendations for teachers how to behave. It depends on the federal state. Some states like Baden-Württemberg or Rhineland-Palatinate do not allow teachers to use Facebook in school contexts. The German Teachers' Alliance has not currently offered guidelines. They only give advice to be cautious. Some schools develop rules for their teachers: For example, creating a second profile on Facebook in case one would like to be connected to students.

In our paper we do not want to discuss different advantages and disadvantages concerning a friendship between teachers and students on Facebook (although it would be an interesting discussion, obviously). Our intention is to analyze processes like this from a media-theoretical point of view. Therefore we are wondering which 
definition of media (devices) can be useful to describe and explain such everyday occurrences as friendships between teachers and students on a social network site. For this purpose we would like to focus on three theoretical approaches:

We regard the situation from a network, a systemic and a semiotic perspective. Of course, this might only give us food for further thought. We concentrate on these three concepts in order to develop a definition of media

- that fits for media in the Information Age

- that focuses on the individual and the structure

- that includes analogue and digital media.

In the following we discuss these approaches and point out their use for describing media offers from each specific theoretical point of view. In addition, we illustrate the analysis by using our example of Facebook. In conclusion we develop a definition of media offers that is based on the three discussed theoretical ideas.

\section{Theoretical approaches}

\section{a) A network perspective}

What is the specific benefit of reflecting media from a network perspective?

In his concept of a network society, Manuel Castells (2000) describes changes in our society: Cultural, economic and political factors led to the power and efficiency that characterize today's networks, for example financial networks. In this understanding networks form the basic units of modern societies. They consist of nodes that are interrelated (Castells 2001b, 432). Nodes can be persons, groups, social movements or enterprises, for example. Thinking in networks means a focus on structures and on processes. Information flows circulate simultaneously and independently from spaces or territories. Networks are open structures and able to add or remove nodes, according to the goals and rules of the network (Castells 2011a, 528; Castells 2005, 7). Networks are not new organizational forms, but digital technologies have changed the character of networks: They became more flexible and adaptive (ibid., 4). According to this concept, traditional institutions, like school, are confronted with these developments and must react. The network society requires an adequate concept of school. «School at the end of the culture of the book» (Böhme 2006) or school in the «Internet Galaxy» (Castells 2001a) must differ from the concept of school that was established in the Industrial Age. Digitization of society influences pedagogical approaches. Inclusion and exclusion are the dominating network operations (Castells 2004, 3). The perception of space and time has changed in the network society. Information and communication technologies, especially the Internet, led space to become a «space of flows» and time a «timeless time» (Castells 2004, 55ff.). Social networks are communication structures. 


\section{What is the specific benefit of Castells' approach regarding our scenario?}

Networks based on information and communication technologies constitute the new social morphology of our society. Social network sites like Facebook are a typical sociological phenomenon. These sites offer people the ability to meet and to connect with others, or rather their profiles. A social network site is based on technical structures.

According to Castells, a confirmed friend request can be interpreted as a relation between two nodes. This possible connectivity only exists within social networks. In other words, only networks make this form of connectivity possible. It cannot be found in an institution like today's school. But a crossing of boundaries seems to be necessary because children and teenagers use information and communication technologies in their everyday life. In a network society, schools no longer have a monopoly on Bildung (Siemens 2005). To survive, schools must become nodes (or even hubs) in globally connected knowledge fields. Faßler describes this kind of development for universities. (Scheibel 2008, 87).

After introducing a network perspective on media we continue with a systemic approach, which also focuses on the social structures.

\section{b) A systems theory perspective What is the specific benefit of reflecting media from a systems theory perspective?}

Niklas Luhmann's $(1984 ; 1988)$ systems theory perspective draws attention to a special way of modeling communication, which is different from our everyday life understanding of communication, e.g. face-to-face communication between people. This perspective allows us to analyze and to explain communication in technically supported networks in mass communication.

Luhmann (1984) observes and describes, in terms of his approach, communication processes from a macro perspective. His system-related perspective shows that communication within a system follows certain rules. A basic assumption observes society as a social system, consisting not of individuals (subjects), but of communication. Correspondingly in these communications, individuals are not involved, but systems, to be more precise psychic systems. Following that, communication does not take place between people, but between communications (31).

For Luhmann, communication is a process of three selections or rather a synthesis of three selections (ibid., $195 \mathrm{ff}$.). Understanding is the ability to differentiate between information and utterance. The first selection refers to information. This means that person A (a psychic system) decides to understand something as information. The second selection refers to the decision to transmit the information. This transmitted information can only be understood by a person - called B - if B can 
distinguish information and utterance, which means that B has to select again (third selection). This «understanding" is not a psychic understanding, but only refers to the selection. This means, that $B$ does not necessarily have to act. It is a selection independent of the understanding.

These contingent selections regarding communication initially make it seem rather improbable for communication to take place. In his theoretical approach Luhmann reduces this improbability through media and distinguishes language, media of dissemination and symbolically generalized communication media (ibid., $220 \mathrm{ff}$.). Language's task is to make the understanding of communication more likely. It widens the scope of communication possibilities beyond mere perception and makes it possible to connect psychic and social systems.

The media of dissemination shall remove restrictions of communication regarding time and space and, thereby increase the addressees' reachability. Examples of dissemination media are writing, printing and electronic broadcasting, which were developed on the basis of language. On the one hand the technology of dissemination media widens communication's scope of action enormously. On the other hand every technology selects and restricts which communication can serve as a basis for further communication (ibid., 221).

The function of symbolically generalized communication media is to arouse motivation to accept communication to ensure success. Symbolically generalized media are media that use generalization in order to symbolize the connection of selection and motivation to depict it as unity. Important examples are: truth, love, property/money, power/right. Though quite differently, all cases are about selecting media so that they additionally function as motivation and thus make sure that the selections offered are accepted. For this reason, Luhmann introduces so called media codes which pre-structure communication and define standards for continuing communication. This makes it possible to assign communication to different fields and motivate the addressee to accept the selection offered to him. Incidents occurring within the environment of a system must be classified as coded/uncoded, because in a communication process only coded incidents work as information and all others are disturbances or noise. The probability to accept a communication increases if the relevant information is coded with the system's own code. The code is a binary scheme (e.g. true/ false in the science system; payment/unpayment in the economical system, ...). 


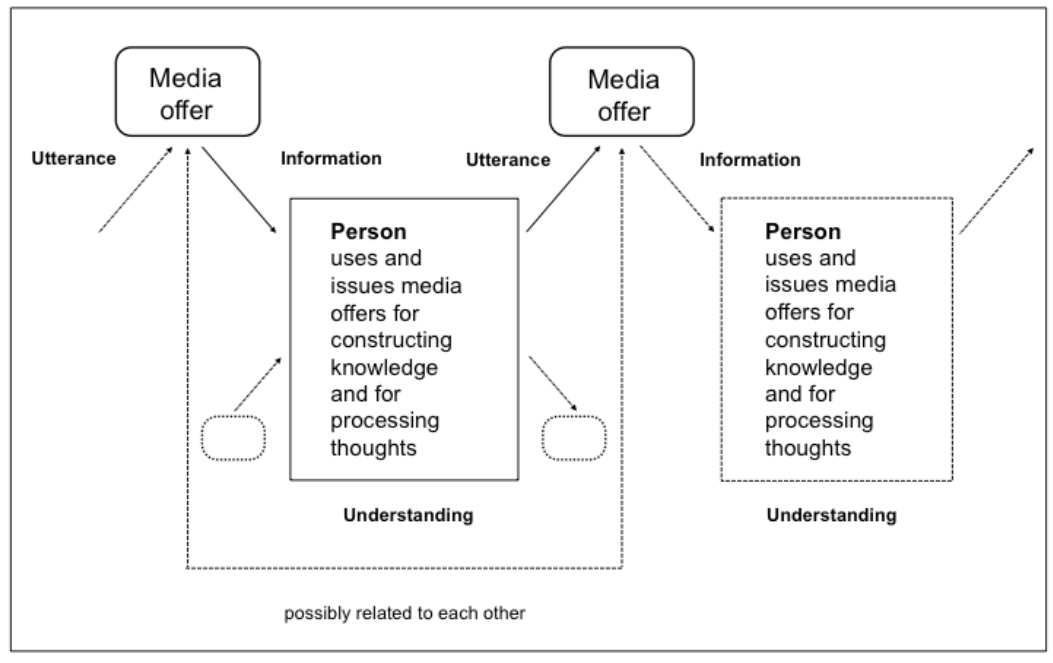

Figure 1: Communication as process of selections.

As shown mediatized communication processes can be characterized as a synthesis of selection processes. We perceive information from our environment, process it, and offer it in the form of media products (utterance). Other participants can understand the offers to select by distinguishing between utterance and information. This process can be continued. The communication's participants do not directly communicate, except, for example, via media offers. These media offers are coded as «potential signs» (see below), hence participants must refer to collective knowledge to decode the communication.

What is the specific benefit of Luhmanns approach regarding our scenario?

Referring back to our Facebook example, an analysis based on systems theory shows two results:

- Systems theory describes communication as communication between communications. In a social network, like Facebook, one can observe that people fade from the spotlight and the media offers come to the forefront. Profiles function as media offers and selections are made by users or possibly by technique. Thus the process of uttering and accepting a friend request is a process of technically supported continued communication.

- In the social network, different types of communication are processing. Facebook is a virtual environment that is no longer an unstable system of interaction (like meeting someone on the street), but shows characteristics of a stable interaction system. Facebook is not a social network that targets a specific target group (like Xing or Linkedln). This means that Facebook is not actually a network, in which people's professional roles are important. 
However, by discussing topics that usually come from an educational system (for example, discussions about Facebook profiles) it addresses people in their professional roles (as teachers and students). Friend requests, which address the communication partner only as person in private and not within their professional role, are opposite to this observation. Personal expectations, role expectations, program specific expectations and expectations due to values overlap and mix. This makes the connecting communication difficult. Simultaneously, it would be worth considerating how a social system should be to facilitate connecting communication.

System theory allows the world to be divided into differentiating communications to describe a reduction of complexity. Communication distinguishes itself by talking about one topic, but keeping silent about every other topic (Luhmann and Fuchs $1989,7)$. Certain topics or guiding differences determine communication, organize discourses and are an expression of different perceptions of the world. These can be established as subsystems, which, with the help of mass media, primarily conduct their own operations, e.g. publishing posts within social networks. Luhmann calls this phenomenon the «reality of construction» $(1996,13)$. On the other hand, these messages appear as reality for others - this is the construction of reality. Mass media as observing systems are compelled to construct reality «namely in contrast to the own reality another» $(1996,18)$. At that point, reality is not considered to be an object, but a horizon. Parallel worlds and their demands for validity are characteristics of subsystems, whose communications underlie different guiding differences, with specific distinctions. Hence, there are communities within the mass medium World Wide Web, which follow the guiding differences education, movement, entertainment, hobby, work, health, etc. They develop an independent existence and connect communication with existing communications.

The theory of autopoietic systems enables a description of the formation of social systems and how they develop, how communicative complexity is reduced, and which part of that is taken by media. Within this view, the participation of a subject is neither necessary nor possible. However, the subject is not basically denied, but society is subordinated by a perception, an observation!), in which the subject is not matter of the consideration referring to an anthropological understanding. This system theoretical perspective describes the attempt to make the complexity of the world comprehensible, and in this case it does not mean to consider every single subject, but to formulate systems and ask for their functions and conditions.

Wherever we are concerned with communication and media offers we are concerned with signs. Therefore it is important to describe media and communication as sign patterns and sign processes. We use a semiotic perspective to do so. 


\section{c) A semiotic perspective}

What is the specific benefit of reflecting media from a semiotic perspective?

The relation between media offers and technique can be described - in the chronological development of technical artifacts - with, the help of semiotics. Even software engineering can be understood as a sign process (Herzig 2001; 2004; 2012, $139 \mathrm{ff}$.). We will focus on the first topic and shortly introduce Peirce's concept of signs (Peirce 1966, p.228) before we interpret the Facebook example referring to this approach.

To describe Peirce's concept of signs we use an example: Imagine you read the word «FRIEND» on a screen. In Peirce's understanding you recognize a sign consisting of three elements, called the triadic relation.

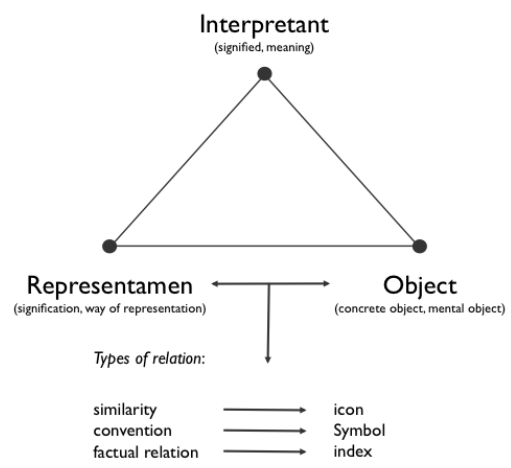

Figure 2: The triadic sign relation according to Peirce.

The representamen is the physical part of the sign, for example, the pixels on the screen. The object is what the sign represents. In this case "friend» can represent a particular person or the idea of a friend, understood in its original (everyday) meaning. The interpretant is developed in the interpreter's consciousness, his understanding of friend or friendship, his experiences with friends or particular friends and so on $(1966,277)$.

One of Peirce's central statements is that a sign is not a sign if it is not interpreted as such. For that reason we speak of possible signs (ibid., 179).

Regarding the relation between representamen and object, Peirce differentiates between icon, symbol and index (Peirce 1991, 64). Whereas iconic signs (e. g. a photo from a building) have a strong similarity with their object (in this case, the building itself), symbolic signs (e.g. a written text) can only be understood when knowing the specific underlying conventions (in this case, the specific language). Finally, indexical signs (e.g. smoke) have a causal relation to their object (in this case fire) (cf. figure 2). With the help of these types of signs, media offers can be described and differentiated in an analytical manner. 
What is the specific benefit of Peirce's approach regarding our scenario?

According to systems theory, social systems consist of communication in which media offers function as selection offers. These offers are inscriptions into language and technology. Peirce's approach allows analyzing these inscriptions, meaning to analyze language as sign system and its use, and to analyze the relation between signs and media as technological artifacts (for examples, see Herzig 2012, $139 \mathrm{ff}$.). By distinguishing different types of signs we can understand media offers, just like Facebook profiles and threads as symbolic and iconic signs. A micro analysis makes it possible to further interpret the single signs as expressions of communication in different systems, for example, youth language and language in professional contexts use specific icons, abbreviations or specific words tailored to the particular group. Referring to cultural studies, we chose a wide text concept as the basis since we find it in Facebook communication referring to symbolic and iconic signs (Barker, 2012). Peirce's approach further allows analyzing friend requests regarding their different meaning. In his approach, Peirce differentiates between a dynamical interpretant and a final interpretant (cf. fig. 3). The dynamical interpretant is further divided into emotional, energetic and logic interpretants. With regard to a friend request in a social network, the emotional interpretant can be seen as the effect of the sign on an emotional level (Hoffmann 2001, 16), for example, in feeling of joy at the interest of a member in the community. The emotional consequence is accompanied by an energetic impact, the confirmation of the request. In that case, the logic interpretant is the construal of the friend request as a sign of interest by another person in oneself, because the other person rates one interesting, likeable, etc. The final interpretant only appears as a logic interpretant, and describes the common meaning of a sign. In case of the friend request the difference between dynamical and final interpretant points out the presumption of the request being a 'real' friend request. This is possibly misleading, since the circumstance that anonymous requests are typically based on information from databases of social networks, which are publicly accessible. In comparison with the common sense of friendship, it is emphasized that the usually linked characteristics of sympathy, trust, shared experiences do not normally apply to the concept of friendship in social networks.

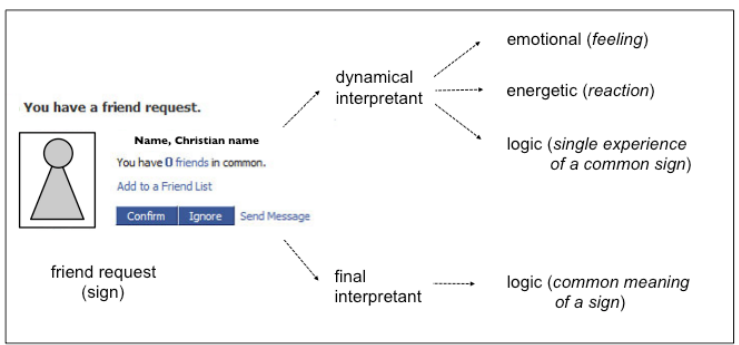

Figure 3: Proper significant outcome of a sign: dynamical and final interpretant (Peirce 1966, 8; Hoffmann 2001). 


\section{Media definition and conclusions}

Digitalization, networking and communication are central concepts in the Information Age. According to this observation, we chose the theoretical approaches of Castells, Luhmann and Peirce to show and discuss their use and range for describing and explaining acting with and via media in a mediatized society. Our definition of media fits for the Information Age, and focuses on the individual and the structure, and includes analog and digital media. This definition of media offers is a useful basis to describe media-related learning-processes in formal, informal and non-formal contexts. The definition is compatible to discourses involving digitalization, networking and communication.

We define media offers as follows:

- Media offers are sign-enabled patterns inscribed into technical devices or material, and/or presented, saved, arranged, copied, transmitted or processed by technique.

- Communication processes are defined by offering and accepting selectionoffers, in other words media offers, as well as by synthesis of information, utterance and understanding.

As a conclusion we are now able to analyze our Facebook example from a mediatheoretical perspective by using the developed definition:

A friend request on a social network site like Facebook is a sign-enabled pattern (words and icons) transmitted and presented by technique. A participant, in this case a Facebook user, assigns meaning to the sign arrangement in a communication process, by offering and accepting requests on the social network site. Furthermore, it is defined by synthesis of information ("You have a friend request.»), utterance (somebody wants to connect to somebody) and understanding (it is possible to confirm or to decline).

This analysis shows that a small phenomenon like a friend request is a complex communication process. It becomes obvious that whether teachers and students should become friends on social network sites like Facebook (cf. Chapter 1) is not very easy to answer. We must take into account that we live in a society that is determined by information and communication technologies, and that is structured in and by networks. From a pedagogical point of view we must weigh the disadvantages and advantages carefully. Therefore, we need to understand the cultural, social and technical processes that occur by using media offers today. Our definition of media according to the ideas of Castells, Luhmann and Peirce is a step in this direction. 


\section{References}

Barker, Chris. 2012. Cultural Studies: Theory and Practice. Thousand Oaks, California: Sage.

BMFSJ [Bundesministerium für Familie, Senioren, Frauen und Jugend], Ed. 2005. Zwölfter Kinder- und Jugendbericht. Bonn: BMFSJ.

Böhme, Janette. 2006. Schule am Ende der Buchkultur. Bad Heilbrunn: Klinkhardt. Castells, Manuel. 2000. The Rise of the Network Society. Volume I: The Information Age: Economy, society and culture. $2^{\text {nd }}$ ed. Oxford: Blackwell Publishers.

Castells, Manuel. 2001a. The Internet Galaxy: Reflections on the Internet, Business and Society. Oxford: University Press.

Castells, Manuel. 2001b. "Bausteine einer Theorie der Netzwerkgesellschaft.» Berliner Journal für Soziologie 4: 423-439.

Castells, Manuel. 2004. "Informationalism, Networks, and the Network Society: A theoretical blueprint.» In The Network Society: A cross-cultural perspective, ed. Manuel Castells, 3-45. Northampton, MA: Edward Elgar.

Castells, Manuel. 2005. «The Network Society: From knowledge to policy.» In The Network Society: From knowledge to policy, ed. Manuel Castells and Gustavo Cardoso, 3-22. Washington, D.C.: Center for Transatlantic Relations.

EuroMeduc, Eds. 2009. Media Literacy in Europe: Controversies, challenges and perspectives. Brussels. http://www.euromeduc.eu/IMG/pdf/Euromeduc_ENG .pdf.

Friesen, Norm and Theo Hug. 2009. "The Mediatic Turn: Exploring concepty for media pedagogy.» In Mediatization: Concept, changes, consequences, ed. Knut Lundby, 63-84. New York: Peter Lang.

Herzig, Bardo. 2001. «Die mit den Zeichen tanzen»: Ein Beitrag zum Verhältnis von informationstechnischer Bildung und Medienerziehung.» MedienPädagogik 4 (14. Nov.): 1-28. www.medienpaed.com/4/\#herzig0111.

Herzig, Bardo. 2004. «Integrative Medienbildung. Ein (semiotischer) Beitrag zu einer integrativen Medienbildungstheorie.» Medienimpulse 48: 21-28.

Herzig, Bardo. 2012. Medienbildung: Grundlagen und Anwendungen. Handbuch Medienpädagogik Bd. I. München: kopaed.

Herzig, Bardo and Silke Grafe. 2007. Digitale Medien in der Schule: Standortbestimmung und Handlungsempfehlungen für die Zukunft. Bonn: Deutsche Telekom AG.

Hoffmann, Michael H.G. 2001. «Peirces Zeichenbegriff: Seine Funktionen, seine phänomenologische Grundlegung und seine Differenzierung.» http://www .uni-bielefeld.de/idm/semiotik/Peirces_Zeichen.html.

Livingstone, Sonia and Moira Bovill, Eds. 2001. Children and Their Changing Media Environment: A European comparative study. Mahwah: Erlbaum. 
Luhmann, Niklas. 1984. Soziale Systeme: Grundriss einer allgemeinen Theorie. Frankfurt a. M.: Suhrkamp.

Luhmann, Niklas. 1988. «Wie ist Bewusstsein an Kommunikation beteiligt?» In Materialität der Kommunikation, hrsg. v. Hans Ulrich Gumbrecht and Karl Ludwig Pfeiffer, 884-905. Frankfurt a. M.: Suhrkamp.

Luhmann, Niklas. 1996. Soziale Systeme. Grundriss einer allgemeinen Theorie. Frankfurt a.M.: Suhrkamp.

Luhmann, Niklas and Peter Fuchs. 1989. Reden und Schweigen. Frankfurt a. M.: Suhrkamp.

Peirce, Charles Sanders. 1966. Collected Papers of Charles Sanders Peirce. Ed. Charles Hartshorne and Paul Weiss, Vol. 1-6. Cambridge: Harvard University Press.

Peirce, Charles Sanders. 1967. Schriften zum Pragmatismus und Pragmatizismus. Hrsg. v. Karl-Otto Apel. Frankfurt a. M.: Suhrkamp.

Peirce, Charles Sanders. 1991. Charles S. Peirce, Schriften zum Pragmatismus und Pragmatizismus. Hrsg. v. Karl-Otto Apel. Frankfurt a. M.: Suhrkamp.

Scheibel, Michael. 2008. Architektur des Wissens. Bildungsräume im Informationszeitalter. München: kopaed.

Siemens, George. 2005. "Connectivism: A learning theory for the digital age.» http://www.elearnspace.org/Articles/connectivism.htm. 